\title{
Treatment of Batik Industry Wastewater Plant Effluent using Nanofiltration
}

\author{
Titik Istirokhatun ${ }^{1,2}$, Heru Susanto ${ }^{1,3 *}$, M. Arief Budihardjo², Elda Septiyani², \\ Aditya Rahmat Wibowo ${ }^{2}$, Eva Fathul Karamah ${ }^{4}$ \\ ${ }^{1}$ Membrane Research Center, Integrated Laboratory for Research and Services, Universitas Diponegoro, Jl. \\ Prof. Soedarto, Tembalang Semarang 50275, Indonesia \\ ${ }^{2}$ Department of Environmental Engineering, Faculty of Engineering, Universitas Diponegoro, Jl. Prof. \\ Soedarto, Tembalang Semarang 50275, Indonesia \\ ${ }^{3}$ Department of Chemical Engineering, Faculty of Engineering, Universitas Diponegoro, Jl. Prof. Soedarto, \\ Tembalang Semarang 50275, Indonesia \\ ${ }^{4}$ Department of Chemical Engineering, Faculty of Engineering, Universitas Indonesia, Kampus UI Depok, \\ Depok 15424, Indonesia
}

\begin{abstract}
In this study, the removal of dyes, sulfide, and some other components in batik wastewater using a nanofiltration (NF) membrane was investigated. Remazol red (RR dye), indigosol brown (IB dye), and sodium sulfide $\left(\mathrm{Na}_{2} \mathrm{~S}\right)$ were used as models of synthetic batik wastewater. Furthermore, NF performance for treating real batik wastewater was also examined. The effects of operating conditions on flux and rejection were investigated. The results showed that all filtration had similar permeate flux behavior, where rapid flux decline was observed at the initial filtration, followed by gradual flux decrease and then reaching a stable flux. The rejections of the pollutant model during NF of synthetic wastewater were $61-76 \%, 90-95 \%$, and $90-99 \%$ for sulfide, IB, and RR, respectively. The color rejection in real batik wastewater was $99.84 \%$. Further, the removal of chemical oxygen demand (COD) reached $87.6 \%$.
\end{abstract}

Keywords: Batik wastewater; Dye removal; Fouling; Nanofiltration; Sulfide removal

\section{Introduction}

Batik is the largest home-based textile industry in Indonesia. Batik is a decorated textile product that combines both art and craft (Anjani et al., 2013; Soesanti and Syahputra, 2016). In principle, selected areas of the cloth are blocked out using hot wax, and the remaining is then dyed or decorated. Thereafter, the dyed cloth is washed to remove the wax using water. The areas covered with wax resist the dye and remain in the original color. Increased batik demand affects the growth and development of batik industry centers in various regions in Indonesia. It consumes much water for the dyeing, fixing, and washing processes. Consequently, many wastewaters containing dye, wax, and other chemicals are produced.

It is commonly known that the esthetic nature of water and aquatic photosynthesis is disturbed by the presence of dyes and alkaline conditions. Furthermore, the presence of color hinders aquatic plant and fish growth. More importantly, most dyes used in the batik

*Corresponding author's email: heru.susanto@che.undip.ac.id, Tel.: +62-247460058; Fax.: +62-247480675 doi: 10.14716/ijtech.v12i4.4645 
industry have complex structures, making them difficult to degrade chemically, biologically, and photo-degradation (Akbari et al., 2002; Punzi et al., 2015; Lu et al., 2019). Therefore, this batik wastewater requires treatment before being discharged into the environment or being reused. Unfortunately, many home-based batik industries in Indonesia discharge their wastewater without proper treatment.

The chemicals used frequently in batik industries include pigments, dyes, and wax. The commonly used textile dyes are derived from azo compounds and benzene derivatives, which require a long time to degrade (Handajani and Narissi, 2016). Saratale et al. (2011) reported that $60-70 \%$ of textiles dye contains azo dyes with $-\mathrm{N}=\mathrm{N}-$ bond. It has been documented that only a small number of dyestuffs are biodegradable, and the residual color from azo dyes is usually low biodegradable due to their insolubility (Al-Kdasi et al., 2004). In addition, azo dyes can be a source of disease due to their carcinogenic and mutagenic properties (Camargo-Ventura et al., 2011). Thus, the removal of dyes and sulfide in batik wastewater is imperative.

Several methods have been proposed to treat textile wastewater, including ozonation (Peralto et al., 1999), photochemical (Peralto et al., 1999), adsorption (Choy et al., 1999), ion exchange (Slokar and Le Marechal, 1997), floatation (Warjito and Nurrohman, 2016), and electrokinetic coagulation (Sharfan et al., 2018). In general, such methods resulted in dye removal efficiencies within the range of 70-95\%. Unfortunately, these processes require large areas or generate a huge volume of hazardous sludge, causing a problem of waste disposal. Therefore, in this study, nanofiltration (NF) is proposed to handle these problems due to its versatile application in wastewater treatment, high efficiency, and environmentally friendly process (Wang et al., 2019).

Rashidi et al. $(2013,2014)$ explored batik wastewater treatment, especially in Malaysia, using physical pretreatment and NF membranes. The chemical oxygen demand (COD) value in the permeate samples was reduced to zero, and the dye removal efficiency exceeded $90 \%$. Nevertheless, they used only synthetic wastewater containing various dyes and waxes. Further, they focused on the removal of dye, wax, and COD, while other substances, such as sulfide and the effect of dissolved salt on process performance, were not discussed. Notably, salt is usually added during dyeing processing in batik production, especially in Indonesia, to produce a brighter Batik color and also to increase the fixation degree of dye on cloth material. More importantly, the dye used by the Batik industry in Indonesia and Malaysia probably differs due to the difference in consumer taste and chemicals used.

In this study, the removal of dyes and sulfide using NF membrane was studied. The effect of salt on flux behavior and removal efficiency was investigated. Remazol red and indigosol brown were used as synthetic dyes, whereas sodium sulfide ( $\mathrm{Na}_{2} \mathrm{~S}$ ) was used as a model of sulfide for preparing synthetic batik wastewater. Material selection was based on their usage in home-based batik industries, especially in Semarang, Indonesia. Furthermore, $\mathrm{NF}$ membrane performance for treating real batik wastewater was examined.

\section{Materials and Methods}

\subsection{Materials}

Remazol red RB.C.I. reactive red 198 (called 'RR') with a molecular weight of 967.5 $\mathrm{g} / \mathrm{mole}$ and indigosol brown IRRD (called 'IB') with a molecular weight of $602.59 \mathrm{~g} / \mathrm{mole}$ were used. $\mathrm{Na}_{2} \mathrm{~S}$ was used for sulfide solution. These materials were obtained from one of the batik industries in Semarang, Indonesia. Sodium chloride $(\mathrm{NaCl})$ was purchased from Unichem Company, Indonesia. Sodium hydroxide $(\mathrm{NaOH}), \mathrm{HCl}, \mathrm{H}_{2} \mathrm{SO}_{4}, \mathrm{FeCl}_{3}$, and $\left(\mathrm{NH}_{4}\right)_{2} \mathrm{HPO}_{4}$ were purchased from Merck, Germany. NF (NF270) membrane made of polypiperazine TFC was used and a gift from DOW Filmtec TM Membranes, USA. Our 
measurement showed that the molecular weight cut-off (MWCO) of this membrane was 352 $\mathrm{g} / \mathrm{mol}$, which parallels that reported in a previous publication (MWCO $=340 \mathrm{~g} / \mathrm{mol}$ ) (LópezMuñoz et al., 2009).

\subsection{Methods}

\subsubsection{Synthetic and real batik wastewater}

To begin, real batik wastewater obtained from one of the batik industries in Semarang, Indonesia, was characterized. Phenomenological study was conducted using synthetic wastewater, which was prepared based on the characteristics of real batik wastewater, while real batik wastewater was used to examine the best process performance obtained during phenomenological study. The synthetic batik wastewater was prepared by dissolving a dye (400-600 Pt Co) or sulfide compound (50-200 mg/L) into distilled water. Both dye and sulfide concentrations were varied. In addition, various concentrations of $\mathrm{NaCl}$ were added to the feed containing sulfide or dye to study the effect of salt on performance behavior.

\subsubsection{NF experiment}

An NF experiment was performed using a lab-scale cross-flow filtration unit, and its protocol followed our previous work (Istirokhatun et al., 2018). To begin, the membranes were compacted by filtering pure water for at least $30 \mathrm{~min}$ at a pressure of 7 bars. Thereafter, the pure water was replaced by batik wastewater as a feed. The feed was pumped into the membrane cell with a certain transmembrane pressure $(4,5$, or 6 bars $)$. In each experiment, a new membrane was used. The flux profile as a function of time was gravimetrically monitored. Dye and sulfide concentrations were analyzed using a visible spectrophotometer. The salt concentration was measured using an electronic portable conductivity meter (Model HI 9228, Hanna, USA). The membrane top surface morphology was observed using the JEOL JSM-6510 LA Scanning Electron Microscope (SEM) with $10 \mathrm{kV}$ applied voltage.

\section{Results and Discussion}

\subsection{Characterization of Real Batik Wastewater}

The characterization of real batik wastewater suggests that almost all parameters exceeded Indonesian environmental regulation (Table 1). Only temperature was within the permissible range. Attention should be paid to color, sulfide, turbidity, COD, biological oxygen demand (BOD), and total dissolved salt (TDS), where their values significantly exceeded the environmental standard. Further analysis showed that the COD to BOD ratio was 5.5. This suggests that the batik wastewater here contained high non-biodegradable organic matter and should be classified as hardly biodegradable effluent. In this context, the role of nonbiological treatment is very important. Thus, NF utilization as a nonbiological process is appropriate.

\subsection{The Effect of Process Parameters on Permeate Behavior}

In this study, the effects of transmembrane pressure (TMP), feed concentration, and salt concentrations on NF performance were investigated. The results are presented in Figures 1, 2, and 3. In general, the effects of TMP, feed concentration, and salt concentration on permeate flux behavior were clearly observed. All filtration showed similar permeate flux behavior, where rapid flux decline was observed during around the first 20 minutes of the filtration, followed by a gradual slight flux decrease with increasing filtration until 1hour filtration. Thereafter, nearly constant flux was observed during the remaining filtration time. 
Table 1 Characteristics of batik wastewater, feed, and permeate and the rejection of NF

\begin{tabular}{|c|c|c|c|c|c|c|}
\hline Parameters & Unit & $\begin{array}{c}\text { Batik } \\
\text { wastewater }\end{array}$ & Feed $^{1}$ & Permeate & $\begin{array}{l}\text { Rejection } \\
(\%)\end{array}$ & $\begin{array}{c}\text { Indonesian } \\
\text { environmental } \\
\text { standard } \\
\end{array}$ \\
\hline $\mathrm{pH}$ & - & 9.8 & n.m. & n.m. & - & $6.0-9.0$ \\
\hline Temperature & ${ }^{\circ} \mathrm{C}$ & 29 & n.m. & n.m. & - & 38 (max) \\
\hline TDS & $\mathrm{mg} / \mathrm{L}$ & 2812 & 2456 & 892.8 & 66.24 & 500 (max) \\
\hline Color & TCU, Pt-Co & 600 & 545 & 0.7 & 99.84 & $50(\max )$ \\
\hline Oil and fat & mg/L & 30 & 24.3 & 0.02 & 99.92 & 3.0 (max) \\
\hline Sulfide & $\mathrm{mgS}^{2-} / \mathrm{L}$ & 73 & 69.7 & 27.7 & 60.26 & 0.3 (max) \\
\hline TSS & $\mathrm{mg} / \mathrm{L}$ & 118 & 67.8 & n.d. & 100 & $50(\max )$ \\
\hline Turbidity & NTU & 907 & 798 & 1.51 & 99.81 & $25(\max )$ \\
\hline COD & $\mathrm{mg} / \mathrm{L}$ & 4256 & 4132 & 517.7 & 87.43 & 150 (max) \\
\hline $\mathrm{BOD}_{5}$ & $\mathrm{mg} / \mathrm{L}$ & 772 & 761 & 104.8 & 86.23 & $60(\max )$ \\
\hline
\end{tabular}

${ }^{1}$ Feed : batik wastewater was filtered using normal filter paper; n.m. : not measured; n.d. : not detected

The increase in TMP increased the flux decline for the filtration of the RR dye solution (notably, although the relative flux decline was larger at higher TMP, the nominal flux remained higher than at lower TMP; the relative flux is the nominal flux divided by the initial water flux for the same membrane). In contrast, the extent of flux decline was decreased by increasing the TMP for the filtration of feed containing sulfide and IB solution (Figure 1). The lowest flux decline for the sulfide removal is because the sulfide solution was alkaline $(\mathrm{pH} \sim 9)$, which has a negative charge. Consequently, interaction by electrostatic repulsion between sulfide ions and the membrane should occur. Notably, the iso-electric point of the PA membrane is 4.2 (Akbari et al., 2002), meaning that at the pH used in this experiment, the membrane should have a negative charge. Also, considering the $\mathrm{Na}_{2} \mathrm{~S}$ molecular weight, it should be permeated more freely through the NF membrane via a sieving mechanism.

The possible phenomena behind the flux decline during filtration of the RR dye solution are that RR dye has a strong interaction (ionic and H-bonding) at the surface of the membrane, especially on nitrogenous fibers such as polyamide. In addition, the RR dye solution size should exceed the average pore size of the NF membrane used; hence, it is possible to deposit on the membrane surface. Therefore, the flux decline during filtration of the RR dye solution was the highest. The increase in TMP increased flux decline. The higher TMP will suppress RR dye-making its deposit on the membrane surface become more compact. This observation was also reported in a previous publication (Akbari et al., 2002). Different phenomena were observed for the filtration of sulfide and IB dye feed solution, where the increase in TMP decreased permeate flux decline. This occurs because, while increased feed pressure increased the driving force-overcoming the membrane resistance-the pressure used could not make the deposited solute on the membrane surface become denser; thus, increased filtration resistance due to cake layer compaction did not occur. Consequently, the permeate flux increased. This finding was also supported by Tang and Chen (2002). Further analysis of the fouling mechanism using the Hermia model (e.g., Ismail et al., 2019) could not be performed in this case due to very small pore size of the NF membrane.

Within the range of concentrations used, the effect of feed concentration on flux decline from the lowest to the highest was demonstrated by sulfide, RR dye, and IB dye solutions, respectively (Figure 2). For all solute models, increased feed concentration decreased the flux ratio, indicating a higher flux decline. The higher feed concentration resulted in higher concentration polarization. Thus, deposition of solute on the membrane surface leading to 
cake/gel layer formation will be more possible. Further, this higher concentration polarization improved the osmotic pressure, which reduced the net TMP, leading to permeate flux reduction. For the filtration of $\mathrm{Na}_{2} \mathrm{~S}$, it may be oxidized, forming larger salt $\mathrm{Na}_{2} \mathrm{SO}_{3}$, as reported by Smincakova and Raschman (2006).
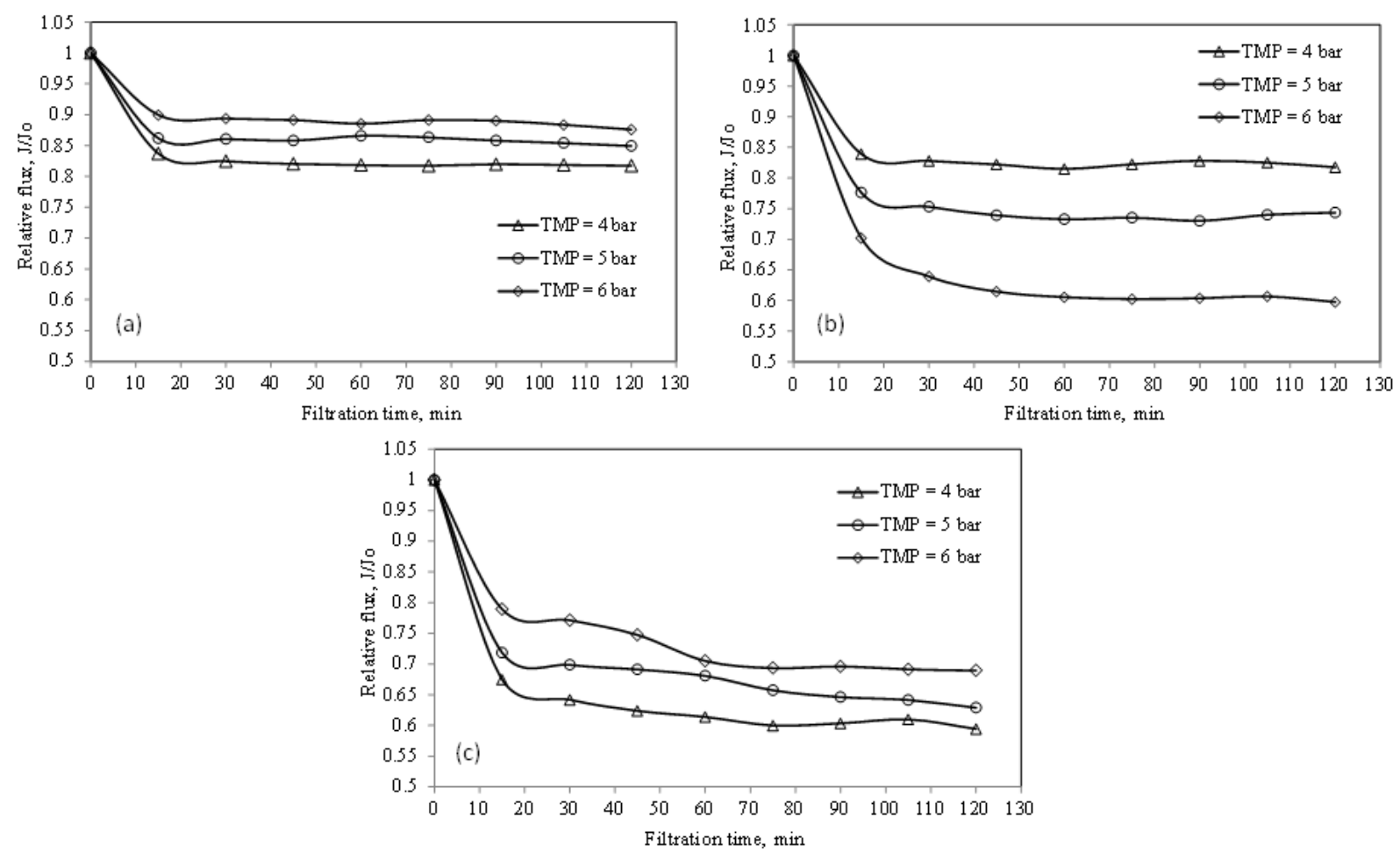

Figure 1 Flux behavior over filtration time at various TMPs for different feed solutions: (a) sulfide solution, $100 \mathrm{mg} / \mathrm{L}$; (b) RR dye solution; 500 Pt-Co, and (c) IB dye solution, $500 \mathrm{Pt}-\mathrm{Co}$

Overall, Figure 3 shows that the presence of $\mathrm{NaCl}$ in the feed solution decreased permeate flux (for sulfide and RR solution filtration). The severity of the flux decline increased with increased $\mathrm{NaCl}$ concentration. This finding agrees with a previous publication by Han et al. (2018). This result occurred because a cake layer was formed at a higher salt concentration due to decreased charge repulsion between the positive charge of $\mathrm{Na}$ and the negative charges of the RR dye and sulfide. Importantly, RR dye is a type of anionic dye with a negative charge. The charge attraction between the positive charge of $\mathrm{Na}$ and the negative charge of the NF 270 membrane was also decreased. The other possible reason is that the presence of $\mathrm{NaCl}$ increased the osmotic pressure, reducing the net TMP.

Another finding is that the presence of $\mathrm{NaCl}$ first increased and then decreased the flux (IB solution). This result parallels that of Li et al. (2019). The presence of salt supports the dispersion of dye molecules more uniformly, thus avoiding dye aggregation (Wang et al., 2013; Li et al., 2019). Hence, concentration polarization near the membrane surface decreased, leading to a permeate flux decline. Nevertheless, at a high salt concentration and smaller dye size, the uniform dispersion molecules increased, causing the possibility of dye molecules entering the NF membrane pores, leading to flux decline. These different results among the previously reported literature and the results obtained here are attributed to the differences in membrane and solute characteristics. 

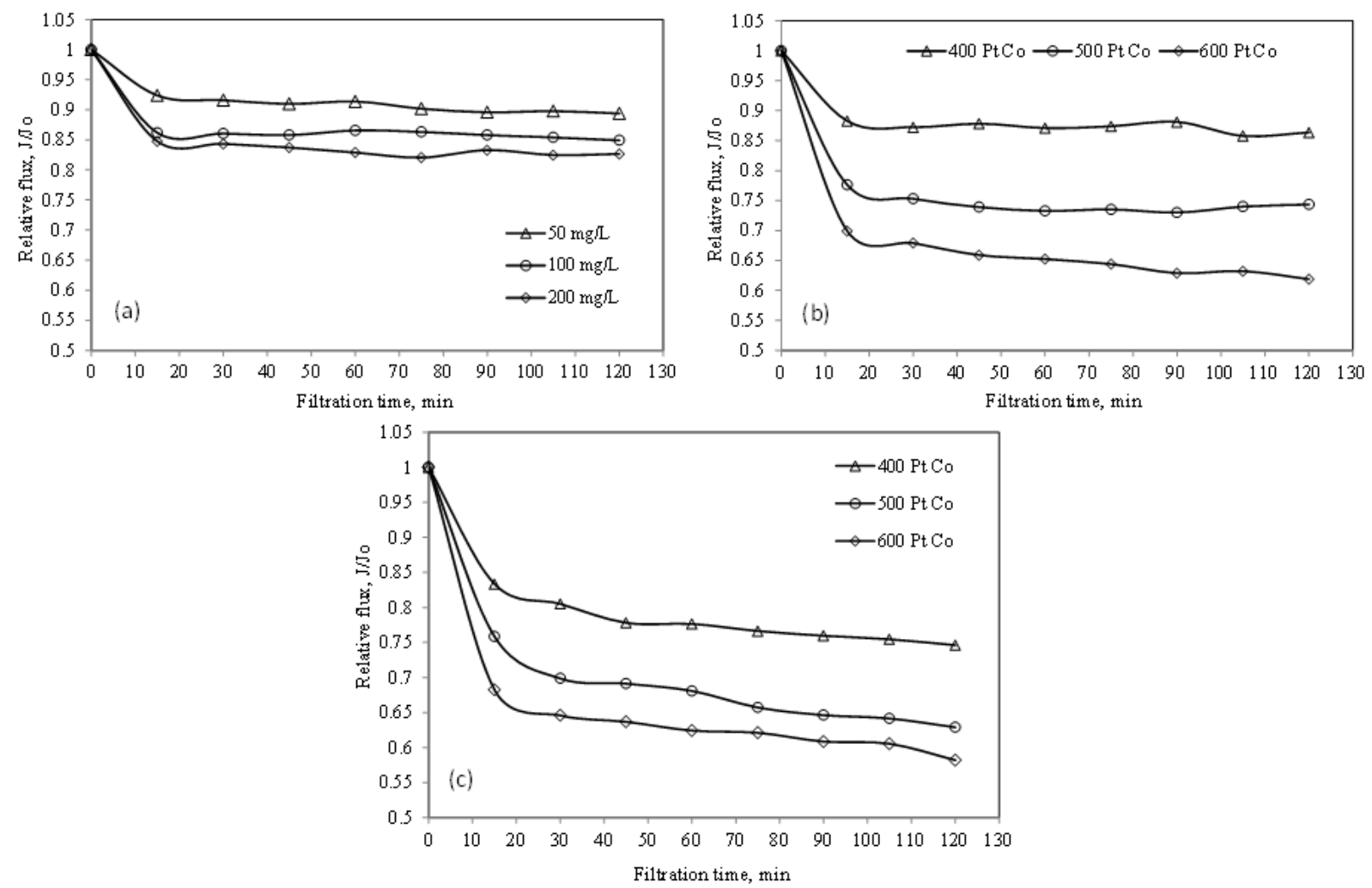

Figure 2 Flux behavior over filtration time at various feed concentrations for different feed solutions: (a) sulfide solution; (b) RR dye solution; (c) IB dye solution. TMP was 5 bars
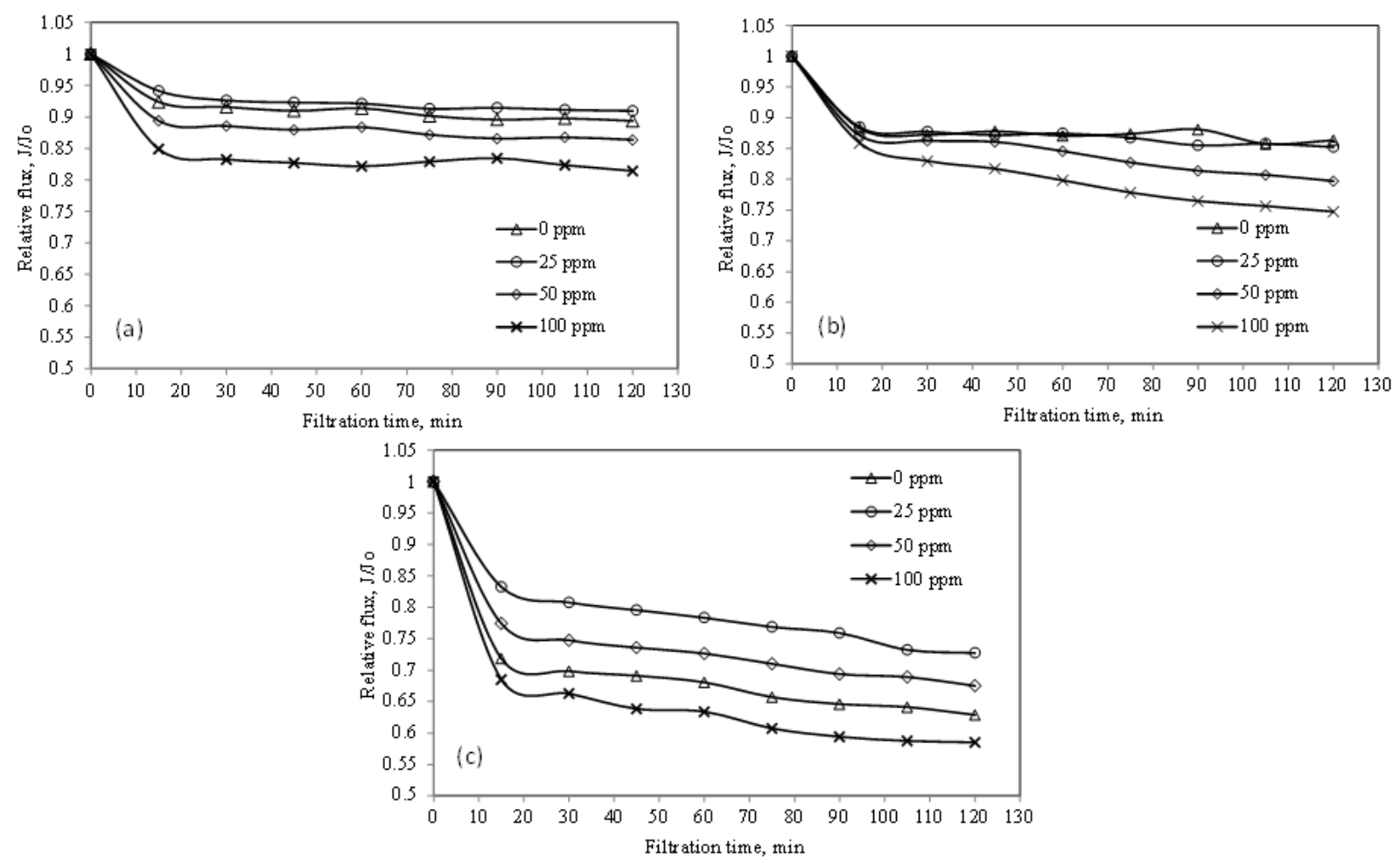

Figure 3 Flux behavior over filtration time at various $\mathrm{NaCl}$ concentrations for different feed solutions: (a) sulfide solution (100 mg/L); (b) RR dye solution (500 Pt Co); and (c) IB dye solution (500 Pt Co). TMP was 5 bars 

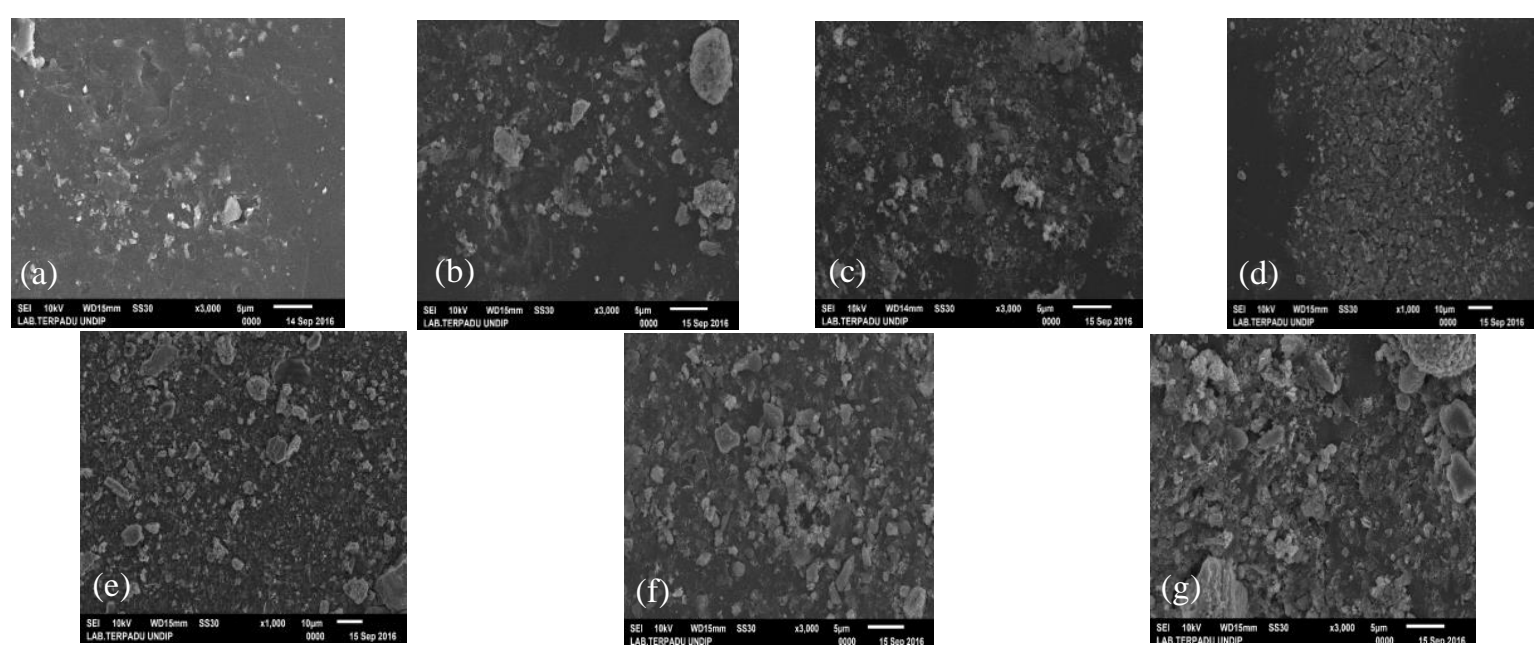

Figure 4 SEM images of (a) fresh membrane and membranes after the filtration of (b) sulfide solution; (c) sulfide solution containing $\mathrm{NaCl}$; (d) RR dye solution; (e) RR dye solution containing $\mathrm{NaCl}$; (f) IB dye solution; and (g) IB dye solution containing $\mathrm{NaCl}$

Overall, the deposition of solids on the membrane surface can be seen using the scanning electron microscope (SEM) results (Figure 4). Further, the effect of $\mathrm{NaCl}$ on the deposition of solids on the membrane surface was also confirmed. Also, dye deposition on the membrane surface was more compact than the sulfide deposition.

\subsection{The Effect of Process Parameters on NF Rejection}

A slight increase in rejection with increasing TMP was observed for sulfide removal $(71.3 \pm 2.4 \%, 72.4 \pm 2.2 \%$, and $73.7 \pm 2.1 \%$ at the TMP of 4,5 , and 6 bars, respectively). For the RR dye solution, the rejection decreased slightly with increasing TMP $(99.4 \pm 1.9 \%$, $97.5 \pm 2.1 \%$, and $95.6 \pm 2.3 \%$ at the TMP of 4,5 , and 6 bars, respectively). Further, the relatively constant rejection was observed for the IB solution $(94.9 \pm 2.2 \%, 93.5 \pm 1.8 \%$, and $92.6 \pm 2.0 \%$ at the TMP of 4,5 , and 6 bars, respectively). Detailed rejection data are presented in the Supplementary Material.

The higher rejection for RR than for IB at the same TMP was attributed to its higher molecular weight. Considering the rejection results, it is reasonable to state that the solute and membrane characteristics were more dominant in influencing the rejection than the operating condition. Also, in membrane processes, where solute separation occurs via the sieving mechanism, the rejection should decrease with increasing TMP.

The sulfide rejections were $63.7 \pm 3.1 \%, 72.4 \pm 2.2 \%$, and $76.5 \pm 2.2 \%$ for feed concentrations of 50,100 , and $200 \mathrm{mg} / \mathrm{L}$, respectively. The rejections of RR dye were $93.2 \pm 3.6 \%, 96.5 \pm 2.1 \%$, and $98.9 \pm 1.9 \%$ for feed concentrations of 400,500 , and $600 \mathrm{Pt} \mathrm{Co}$, respectively. The rejections of IB dye were $91.1 \pm 2.4 \%, 93.5 \pm 1.8 \%$, and $94.2 \pm 1.5 \%$ for feed concentrations of 400,500, and $600 \mathrm{Pt}$ Co, respectively. The increase in solute rejection with increasing feed concentration suggests that the mass transfer is not driven by the solution diffusion mechanism. The higher feed concentration resulted in more significant concentration polarization built on the membrane surface, leading to gel/cake formation due to adsorption. This adsorption is derived from ionic and H-bonding that occurs on the membrane surface (Akbari et al., 2002). Further, the formed gel increased the retained dye on the membrane surface and then allowed the increasing rejection of dye along with increasing feed concentration. The increase in sulfide rejection might be related to the phenomenon in which electrostatic repulsion between sulfide and the membrane surface 
increased with increasing sulfide concentration. Hence, the rejection of sulfide increased with increasing feed concentration.

The presence of $\mathrm{NaCl}$ decreased the rejection of all pollutant models. The sulfide rejections were $66.4 \pm 2.2 \%, 64.2 \pm 1.9 \%, 63.8 \pm 2.6 \%$, and $61.6 \pm 3.1 \%$ for $\mathrm{NaCl}$ concentrations of $0,25,50$, and 100 , respectively. The rejections of RR were $96.5 \pm 2.1 \%, 95.1 \pm 2.5 \%$, $93.6 \pm 3.2 \%$, and $90.2 \pm 2.9 \%$ for $\mathrm{NaCl}$ concentrations of $0,25,50$, and 100 , respectively. The rejections of IB were $93.5 \pm 1.8 \%, 91.2 \pm 2.1 \%, 90.8 \pm 2.6 \%$, and $89.5 \pm 3.3 \%$ for $\mathrm{NaCl}$ concentrations of $0,25,50$, and 100 , respectively. However, the declining level of rejection for sulfide exceeded those of RR and IB dyes. The presence of salt increased the osmotic pressure and then reduced the net driving force. Thus, the amount of water on the permeate side decreased and then lowered the solute rejection. Furthermore, as explained by Li et al. (2019), the $\mathrm{NaCl}$ concentration increased the uniformity of dye dispersion, leading to increased solute diffusion through the membrane pores. In addition, the presence of $\mathrm{NaCl}$, especially at high concentrations, caused the phenomenon of Donnan exclusion to decrease, decreasing the electrostatic attraction (Akbari et al., 2002). It was reported that the effect of charge interaction decreased when the NF membrane was close to neutral. In this context, size exclusion, solute diffusion, and intermolecular interactions of the dye molecules play a mass transfer role (Wang et al., 2017; Zhang, 2019).

\subsection{Treatment of Real Batik Wastewater}

After pretreatment using normal filter paper, the real batik wastewater was used as the feed. Figure 5 displays the time-dependent water flux during the filtration of real batik wastewater. Three modes of filtration were performed. In mode 1, filtration was performed, and at certain times $(5.5,15.5,25.5$, and $35.5 \mathrm{~h})$, the filtration was stopped for $5 \mathrm{~min}$ and then was restarted. This protocol aimed to investigate the contribution of concentration polarization. Mode 2 involved filtration and cleaning using pure water at certain times (5.5, $15.5,25.5$, and $35.5 \mathrm{~h}$ ). In mode 3 , the experiment was performed as in mode 2 , but $\mathrm{NaOH}$ $0.01 \mathrm{M}$ was used instead of water for cleaning.

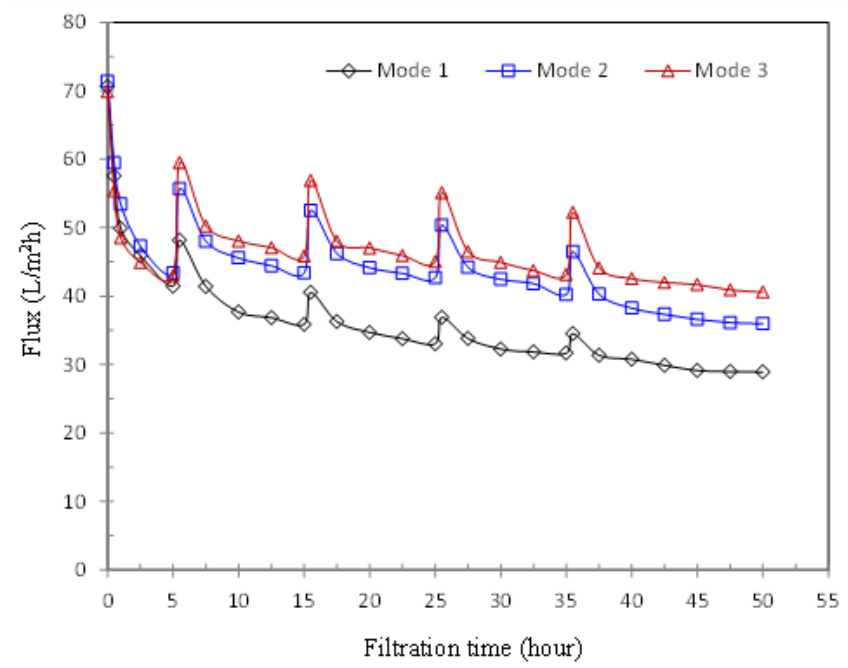

Figure 5 Flux behavior during filtration of real batik wastewater (TMP = 5 bars). Cleaning was performed at a pressure of 0.5 bar for 5 min

In general, all modes showed similar flux behavior, where flux decline at the beginning of filtration was observed. Running an experiment without cleaning resulted in a stable flux of about $\sim 41 \%$ of the initial pure water flux after $40 \mathrm{~h}$ filtration. Stopping the filtration at $5.5,15.5,25.5$, and $35.5 \mathrm{~h}$ and restarting the filtration increased the permeate flux by 16.3 , 
13.0, 11.7, and 9.0\%, respectively. Performing external cleaning with water instead of stopping the filtration for the same time increased the flux of 28.3, 21.1, 18.0, and 15.5\%. The obtained stable flux was about $50.6 \%$. When $\mathrm{NaOH}$ was used for external cleaning instead of water, the increase in flux after external cleaning was higher than when using water, i.e., 38.4, 24.1, 22.5, and 21.1\%.

These results suggest the significant contribution of concentration polarization to flux decline and reveal that periodic external cleaning using water could improve the permeate flux. $\mathrm{NaOH}$ utilization instead of water during external cleaning further increased the permeate flux. These phenomena proved the cake layer formation on the membrane surface. Complete rejection (100\%) was shown for suspended solid, while high rejection (more than 99\%) was demonstrated for three components: color, turbidity, and oil and fat (see Table 1). In general, the rejection of real batik wastewater exceeded that of synthetic wastewater for all pollutant models. This suggests that the interaction among solids in feed influenced the membrane rejection. Regardless of the interaction mechanism, a more complex system in real batik wastewater may reduce the charge exclusion or increase the solute size, leading to higher rejection.

\section{Conclusions}

The effects of TMP, feed concentration, and salt concentration on permeate flux behavior were observed. All filtrations showed similar permeate flux behavior, where rapid flux decline was observed at the initial filtration, followed by a gradual slight flux decrease with increasing filtration time, reaching a stable flux. No significant effect of TMP on solute rejection was observed for all pollutant models. In contrast, the solute rejection kept decreasing with increasing feed concentration alongside $\mathrm{NaCl}$ concentration. Concentration polarization contributed significantly to the flux decline, but fouling via gel or cake layer formation still dominated the cause of flux decline. Thus, a periodic external cleaning was important to be conducted from a practical viewpoint.

\section{Acknowledgements}

The authors thank the Ministry of Research, Technology, and Higher Education of the Republic of Indonesia (grant number 101-165/UN7.P4.3/PP/2019) for funding this research. The authors would also like to thank USAID through the Sustainable Higher Education Research Alliance (SHERA) Program for the Universitas Indonesia SMART CITY project for the opportunity to increase the quality of this research.

\section{References}

Akbari, A., Remigy, J.C., Philippe, A., 2002. Treatment of Textile Dye Effluent using a Polyamide-Based Nanofiltration Membrane. Chemical Engineering and Processing, Volume 41(7), pp. 601-609

Al-Kdasi, A., Idris, A., Saed, K., Guan, C.T., 2004. Treatment of Textile Wastewater by Advanced Oxidation Processes-A Review. Global Nest the International Journal, Volume 6(3,) pp. 222-230

Anjani, S., Hidayat, R., Adlan, Y.A., Suzianti, A., Hapsari, R.T., 2013. Design of Ergonomic Stool (Dingklik) for Batik Crafters. International Journal of Technology, Volume 4(3), pp. 299305

Camargo-Ventura, B.D.C, Maltempi, P.P.P., Marin-Morales, M.A., 2011. The Use of the Cytogenetic to Identify Mechanisms of Action of an Azo Dye in Allium Cepa 
Meristematic Cells. Journal of Environmental \& Analytical Toxicology, Volume 1(3), pp. 5-12

Choy, K.K.H., McKay, G., Porter, J.F., 1999. Sorption of Acid Dyes from Effluents using Activated Carbon. Resources Conservation \& Recycling, Volume 27(1-2), pp. 57-71

Han, G., Chung, T.S., Weber, M., Maletzko, C., 2018. Low-Pressure Nanofiltration Hollow Fiber Membranes for Effective Fractionation of Dyes and Inorganic Salts in Textile Wastewater. Environmental Science \& Technology, Volume 52(6), pp. 3676-3684

Handajani, J., Narissi, D.H., 2016. Analyze the Expression of Cytokeratin 5 on the Epithelial Cells of the Buccal Mucosa in Batik Workers. International Journal of Science and Research, Volume 5(2), pp. 510-515

Ismail, F.H., Marpani, F., Othman, N.H., Nik Him, N.R., 2019. Simultaneous Separation and Biocatalytic Conversion of Formaldehyde to Methanol in Enzymatic Membrane Reactor. Chemical Engineering Communications, Volume 208, pp. 636-645

Istirokhatun, T., Dewi, M.N., Ilma, H.I., Susanto, H., 2018. Separation of Antiscalants from Reverse Osmosis Concentrates using Nanofiltration. Desalination, Volume 429, pp. 105-110

Li, Q., Liao, Z., Fang, X., Wang, D., Xie, J., Sun, X., Wang, L., Li, J., 2019. Tannic AcidPolyethyleneimine Crosslinked Loose Nanofiltration Membrane for Dye/Salt Mixture Separation. Journal of Membrane Science, Volume 584, pp. 324-332

López-Muñoz, M.J., Sotto, A., Arsuaga, J.M., Van der Bruggen, B., 2009. Influence of Membrane, Solute and Solution Properties on the Retention of Phenolic Compounds in Aqueous Solution by Nanofiltration Membranes. Separation and Purification Technology, Volume 66, pp. 194-201

Lu, Z., Hu, F., Li, H., Zhang, X., Yu, S., Liu, M., Gao, C., 2019. Composite Nanofiltration Membrane with Asymmetric Selective Separation Layer for Enhanced Separation Efficiency to Anionic Dye Aqueous Solution. Journal of Hazardous Materials, Volume 368, pp. 436-443

Peralto-Zamora, P., Kunz, A., Gomez de Morales, S., Pelegrini, R., de Capos Moleiro, P., Reyes, J., Duran, N., 1999. Degradation of Reactive Dyes I. A Comparative Study of Ozonation, Enzymatic and Photochemical Processes. Chemosphere, Volume 38, pp. 835-852

Punzi, M., Nilsson, F., Anbalagan, A., Svensson, B.-M., Jönsson, K., Mattiasson, B., Jonstrup, M., 2015. Combined Anaerobic-Ozonation Process for Treatment of Textile Wastewater: Removal of Acute Toxicity and Mutagenicity. Journal of Hazardous Materials, Volume 292, pp. 52-60

Rashidi, H.R., Sulaiman, N.M.N., Hashim, N.A., Hassan, C.R.C., Ramli, M.R., 2014. Synthetic Reactive Dye Wastewater Treatment by using Nano-Membrane Filtration. Desalination Water Treat, Volume 55(1), pp. 1-10

Rashidi, H.R., Sulaiman, N.M.N., Hashim, N.A., Hassan, C.R.C., 2013. Synthetic Batik Wastewater Pretreatment Progress by using Physical Treatment. Advanced Materials Research, Volume 627, pp. 394-398

Saratale, R.G., Saratale, G.D., Chang, J.S., Govindwar, S.P., 2011. Outlook of Bacterial Decolorization and Degradation of Azo Dyes: A Review. Journal of the Taiwan Institute of Chemical Engineers, Volume 42(1), pp. 138-157

Sharfan, N., Shobri, A., Anindria, F.A., Mauricio, R., Tafsili, M.A.B., 2018. Treatment of Batik Industry Waste with a Combination of Electrocoagulation and Photocatalysis. International Journal of Technology, Volume 9(5), pp. 936-943

Slokar, Y.M., Le Marechal, A.M., 1997. Methods of Decoloration of Textile Wastewaters. Dyes and Pigments, Volume 37(4), pp. 335-356 
Smincakova, E., Raschman, P., 2006. Leaching of Natural Stibnite using $\mathrm{Na}_{2} \mathrm{~S}$ and $\mathrm{NaOH}$ Solutions. International Journal of Energy Engineering, Volume 1(2), pp. 85-89

Soesanti, I., Syahputra, R., 2016. Batik Production Process Optimization using Particle Swarm Optimization Method. Journal of Theoretical and Applied Information Technology, Volume 86(2), pp. 272-278

Tang, C., Chen, V., 2002. Nanofiltration of Textile Wastewater for Water Reuse. Desalination, Volume 143(1), pp. 11-20

Wang, J., Zhu, J., Tsehaye, M.T., Li, J., Dong, G., Yuan, S., Li, X., Zhang, Y., Liu, J., der Bruggen, B.V., 2017. High flux Electroneutral Loose Nanofiltration Membranes based on Rapid Deposition of Polydopamine/Polyethyleneimine. Journal of Materials Chemistry A, Volume 28, pp. 14847-14857

Wang, J., He, R., Han, X., Jiao, D., Zhu, J., Lai, F., Liu, X., Liu, J., Zhang, Y., Van der Bruggen, B., 2019. High Performance Loose Nanofiltration Membranes Obtained by a Catecholbased Route for Efficient Dye/Salt Separation. Chemical Engineering Journal, Volume 375, DOI: 10.1016/j.cej.2019.121982

Wang, L., Wang, N., Zhang, G., Ji, S., 2013. Covalent Crosslinked Assembly of Tubular Ceramic-Based Multilayer Nanofiltration Membranes for Dye Desalination. AIChE Journal, Volume 59, pp. 3834-3842

Warjito, W., Nurrohman, N., 2016. Bubble Dynamics of Batik Dyeing Waste Separation using Flotation. International Journal of Technology, Volume 7(5), pp. 898-909

Zhang, N., Jiang, B., Zhang, L., Huang, Z., Sun, Y., Zong, Y., Zhang, H., 2019. Low-Pressure Electroneutral Loose Nanofiltration Membranes with Polyphenol-Inspired Coatings for Effective Dye/Divalent Salt Separation. Chemical Engineering Journal, Volume 359, pp. $1442-1452$ 